\title{
O pensamento computacional e algumas questões da OBMEP como Metodologias inovadoras para as aulas de Matemática
}

\author{
Natália Bernardo Nunes ${ }^{1}$, Aline Silva De Bona ${ }^{1}$ \\ ${ }^{1}$ Instituto Federal de Educação, Ciência e Tecnologia do Rio Grande do Sul - Campus Osório \\ - Osório - RS - Brasil \\ nataliabernunes@gmail.com, aline.bona@osorio.ifrs.edu.br
}

\begin{abstract}
This article reports a research of investigative activities with the use of computational thinking through the plugged and unplugged resources, tied to the Brazilian Mathematics Olympiad of Public Schools (OBMEP) to assist teachers, facing a gap in the Brazilian educational system, especially in math classes. With an action research methodology, after the search of guiding resources, it was realized an elaboration of activities while testing with teachers at the educational level. It covered 19 activities fulfilling the requests, presented to 32 teachers. Of them. 30 were interested in applying to their students in remote teaching.
\end{abstract}

Resumo. $O$ presente artigo relata uma pesquisa de atividades investigativas com o uso do pensamento computacional, através de recursos da computação plugada e desplugada, atrelado a questões da Olimpíada Brasileira de Matemática das Escolas Públicas (OBMEP) para auxiliar docentes, diante de uma defasagem no sistema educacional brasileiro, principalmente nas aulas de matemática. Com uma metodologia de pesquisa-ação, após a busca por recursos norteadores, foi realizada a elaboração de atividades paralela à testagem com professores do nível de ensino. Foram elaboradas 19 atividades cumprindo os requisitos, apresentadas para 32 professores. Destes, 30 demonstraram interesse em já aplicá-las a seus educandos de forma remota.

\section{Introdução}

A Geração Z, ou Nativos Digitais, é a faixa etária de indivíduos que não diferenciam mais a sua vida física de sua vida virtual, já que ambas estão altamente atreladas e não existe mais justificativa para pensar cada uma separadamente [Palfrey e Gasser, 2011]. Nesse sentido, as novas tecnologias apresentam-se como elemento essencial diante da atualidade e um recurso cada vez mais recorrente no cotidiano dos indivíduos em todos os segmentos da sociedade. Entretanto, ao adentrar no setor educacional, observa-se que as atuais metodologias são praticamente as mesmas desde o século XIX, conforme afirma a psicóloga e presidente do Instituto Ayrton Senna, Viviane Senna, em uma entrevista para o BBC News [Costas, 2015].

Considerando esse referencial, alinhado ao desdobramento de pesquisas anteriores, a presente pesquisa apresenta o uso de computação plugada e desplugada para o desenvolvimento de atividades de apoio para as aulas de matemática, aprofundando-se em questões de materiais da Olimpíada Brasileira de Matemática das Escolas Públicas (OBMEP).

\section{O pensamento computacional e a OBMEP}

O termo "pensamento computacional", segundo Wing (2006) "Representa uma atitude e um conjunto de habilidades universalmente aplicáveis, não apenas para cientistas da computação". Pasqual Júnior (2020) e Brackmann (2017) dividem o pensamento computacional em 4 pilares: decomposição, abstração, algoritmos e reconhecimento de 
padrões. Esses pilares sustentam sua teoria e os benefícios e contradições que a introdução do pensamento computacional trará para a sociedade, a educação e a indústria.

Paralelamente aos estudos apresentados, ocorre a OBMEP desde o ano de 2005, sendo uma política pública que atinge $99 \%$ dos municípios brasileiros e possui dentre os seus objetivos "Contribuir para a melhoria da qualidade da educação básica, possibilitando que um maior número de alunos brasileiros possa ter acesso a material didático de qualidade" [OBMEP. 2021]. De acordo com as afirmações levantadas, o pensamento computacional está citado na Base Nacional Comum Curricular (BNCC) [BNCC, 2018] como uma inovação para os métodos educacionais, principalmente na disciplina de matemática.

\section{Objetivos}

Como objetivo principal, visa-se elaborar uma alternativa educacional que auxilie professores de matemática a desenvolverem metodologias inovadoras para seus estudantes. Para isso, foram elaboradas questões que abordem o raciocínio utilizado na OBMEP para explorar o pensamento computacional.

Desta forma, especificamente, a pesquisa pretende construir um material didático, elaborado com as atividades mencionadas acima e com o auxílio de professores da região em que a pesquisa é realizada, por meio de testagens da eficiência das metodologias que serão propostas. Objetiva-se fornecer no material, além de atividades, moldes e sugestões de materiais para a execução das mesmas.

\section{Metodologia}

Para o cumprimento dos objetivos propostos, foram elaboradas atividades com motivação em questões da OBMEP, e aquelas já finalizadas eram encaminhadas a docentes da escola básica, para a realização de apontamentos e correções no que foi desenvolvido. Essa seção apresentará a execução de cada etapa para a elaboração do estudo e o desenvolvimento do produto final.

\subsection{Pesquisa por recursos}

Foram analisadas plataformas de computação desplugada que possuem o pensamento computacional de alguma maneira em sua abordagem. Já para as atividades de computação plugada, uma busca semelhante proporcionou uma limitação, já que grande parte dos softwares encontrados eram atividades limitadas a apenas resolver uma situação problema, e não para servir como material de apoio ao professor. Após a etapa da análise das plataformas e dos recursos das quais utilizam, foi realizada uma busca por materiais de estudo da OBMEP que abordassem problemas investigativos, sendo selecionadas as provas da primeira e segunda fase de todas as edições e os bancos de questões de todas as edições. Com esses materiais, foi elaborado um banco de dados com todas as atividades fornecidas por eles.

\subsection{Elaboração das atividades}

Com a leitura dos problemas investigativos, foram elaboradas atividades autorais, com temáticas, conteúdos e abordagens variadas, que possuíssem como motivação as 
encontradas nos materiais da OBMEP. A abordagem envolvia, além dos materiais já citados, tabuleiros de xadrez, material dourado, o próprio corpo do estudante, controle remoto, jogos digitais e softwares como Geogebra ${ }^{1}$, Khan Academy ${ }^{2}$ e code.org ${ }^{3}$. Para isso, era encontrada alguma questão da olimpíada, resolvida, interpretada e utilizada determinada ideia para elaborar uma questão totalmente diferente, pois, quando abordava o mesmo conteúdo de matemática, possuía uma lógica diferente abordando o Pensamento Computacional e, quando a lógica para resolução era semelhante, alterava-se de um conteúdo de análise combinatória para aritmética e geometria plana, por exemplo.

\subsection{Testagem das atividades}

Paralelo à construção das atividades, encontros via videochamada foram realizados para apresentar as questões a 40 professores da Escola Básica, Esses encontros eram realizados na oportunidade de um curso remoto de formação docente, onde as atividades eram discutidas para aulas presenciais, remotas e o ensino híbrido, sendo as possibilidades existentes na atualidade onde a defasagem do ensino torna-se ainda maior em decorrência do COVID-19.

\section{Resultados}

Ao longo do desenvolvimento do projeto, foram elaboradas 19 atividades, sendo 15 envolvendo computação desplugada e 4 envolvendo computação plugada, mas todas com a apresentação de um dos quatro pilares do pensamento computacional e com motivação no banco de dados selecionado na metodologia com questões da OBMEP. Cada atividade possui a indicação de qual(is) pilar(es) do pensamento computacional estão presentes, bem como qual questão do banco de dados foi utilizada como motivação para a mesma.

\subsection{Testagem das atividades no curso remoto de formação docente}

Dos 45 docentes inscritos, 32 deles participaram de forma ativa. Destes, apenas 2 tiveram receio em usar as atividades propostas em suas turmas de forma remota. Os demais já queriam as atividades para usar em suas aulas como um problema motivador a iniciar um conteúdo ou o próprio ano letivo nestes novos moldes pandêmicos como classificaram.

São muitas as atividades criadas e que os professores querem usar nas suas salas de aula. Isso criou espaço e ideias para os professores elaborarem suas próprias questões, além de associar a projetos e atividades integradas, com particularidades de cada escola e ano escolar. Destaca-se que as professoras e professores da escola básica preferem sempre as desplugadas, por atenderem a maioria dos estudantes, e também por ser possível adaptações aos estudantes com qualquer necessidade específica, como Déficit de Atenção que é muito comum segundo este grupo de professores. Os docentes também destacam que gostam das atividades plugadas para ter ideias e criar outras atividades.

\footnotetext{
${ }^{1}$ Disponível em: <https://www.geogebra.org/?lang=pt>

${ }^{2}$ Disponível em: <https://pt.khanacademy.org/>

${ }^{3}$ Disponível em: <https://code.org/>
} 


\section{Conclusão}

Inicialmente, a pesquisa surge da necessidade de promover uma melhor educação matemática e de atrelar a disciplina de matemática e sua importância ao mundo de hoje através da cultura digital, valendo-se da resolução de problemas investigativos integrados a uma atividade desplugada e, se possível, em seguida, plugada, para fins de mobilizar o processo de aprendizagem e desmistificar aos poucos a ciência da matemática, como disciplina sozinha ou como projetos integrados.

No entanto, um resultado da pesquisa-ação é que a metodologia abordada para a atividade desplugada, seja presencial e/ou remota, é o elemento chave, ou seja, o que faz toda a diferença na aplicação das atividades construídas. $O$ banco de dados com materiais da OBMEP é muito rico aos professores de matemática, mas que carece aos mesmos suporte teórico para realizar a transposição didática das questões da olimpíada à sua sala de aula e fazendo uso dos apontamentos teóricos aqui apresentados (resolução de problemas investigativos e pilares do pensamento computacional). O interesse dos professores e a vontade de mudar suas práticas de sala de aula é confirmado, o que legitima a inédita contribuição da pesquisa, inclusive numa perspectiva da aprendizagem criativa ou melhor "pensar fora da caixa".

\section{Referências}

BNCC (2018) Base Nacional Comum Curricular. http://basenacionalcomum.mec.gov.br/images/BNCC_EI_EF_110518_versaofinal_si te.pdf, Março/2021.

Brackmann, C. P. "Desenvolvimento do pensamento computacional através de atividades desplugadas na educação básica". 2017. 226 f. Tese (Doutorado em Informática na Educação) - Centro Interdisciplinar de Novas Tecnologias na Educação, Universidade Federal do Rio Grande do Sul, Porto Alegre, 2017.

Costas, R. (2015) Modelo de escola atual parou no século 19, diz Viviane Senna. https://www.bbc.com/portuguese/noticias/2015/06/150525 viviane senna ru, Março/2021.

OBMEP (2021)Apresentação. http://www.obmep.org.br/apresentacao.htm, Março/2021.

Palfrey, J. e Gasser, U. (2011) Nascidos na era digital: entendendo a primeira geração de nativos digitais. Artmed: Porto Alegre, Brasil.

Pasqual Júnior. P. A. (2020) Pensamento Computacional e Tecnologias - Reflexões sobre a educação no século XXI. Educs: Caxias do Sul, Brasil.

Wing, J. (2006) Computational thinking. Communications of the ACM, v. 49, n. 3, págs. 33-35. Disponível em: <dl.acm.org/citation.cfm?id=1118215>. Acesso em: 08 mar. 2021. 